\title{
Efeitos da Injeção de Solução Bicarbonatada de Ácido Acetilsalicílico em Mucosa Colorretal de Coelhos, com vistas a Aplicação no Preparo Pré-Operatório do Cólon
}

\author{
Local Effects of Rectal Washout With Acetylsalicylic Acid Solution \\ on the Colonic Mucosa of Rabbits
}

\author{
ENRICO SALOMÃO IORIATTI ${ }^{1}$, MARIA A. M. RODRIGUES ${ }^{2}$, JULIANA MENEZES SIQUEIRA ${ }^{3}$, \\ ROGÉRIOSAAD HOSSNE ${ }^{4}$
}

\begin{abstract}
${ }^{1}$ Aluno do $5^{0}$ ano de graduação em Medicina, bolsista de IC FAPESP - FM Botucatu - UNESP; ${ }^{2}$ Professora Titular do Departamento de Patologia - FM Botucatu - UNESP; ${ }^{3}$ Aluna do $5^{0}$ ano de graduação em Medicina- FM Botucatu UNESP; ${ }^{4}$ Professor Doutor do Departamento de Cirurgia e Ortopedia - FM Botucatu - UNESP.
\end{abstract}

\begin{abstract}
IORIATTI ES; RODRIGUES MAM; SIQUEIRA JM; HOSSNE RS. Efeitos da Injeção de Solução Bicarbonatada de Ácido Acetilsalicílico em Mucosa Colorretal de Coelhos, com Vistas a Aplicação no Preparo Pré-Operatório do Cólon Rev bras Coloproct, 2007;27(4): 439-445.

Resumo: Introdução: A recidiva local no câncer colorretal tem como principal causa o implante de células tumorais nas anastomoses. ${ }^{11-15}$ Dessa maneira, lavagem química do lúmen intestinal é preconizada para evitar tanto o implante quanto à recidiva local. ${ }^{11-28} \mathrm{Em}$ estudos prévios constatamos que a solução bicarbonatada de ácido acetilsalicílico tem efeitos citolíticos e anti-tumorais in-vitro. ${ }^{31}$ Objetivos: Avaliar a toxicidade da solução de aspirina na mucosa colônica de coelhos com o objetivo de usá-la no preparo intestinal de portadores de câncer colorretal. Materiais e Métodos: Foram utilizados 20 coelhos. Um clampe vascular foi colocado acima do cólon sigmóide. Os animais foram submetidos a um enema com $50 \mathrm{ml}$ da solução de aspirina ou soro fisiológico de acordo com o grupo. Os animais foram sacrificados ao término do procedimento ou tardiamente de acordo com o grupo. Resultados: A solução de aspirina não altera a mucosa colônica de coelhos. Conclusão: O uso da solução bicarbonatada de ácido acetilsalicílico no preparo intestinal de portadores de câncer colorretal é clinicamente possível.
\end{abstract}

Descritores: Câncer; Cólon; Recidiva Local; Lavagem do Lúmen Intestinal; Aspirina.

\section{INTRODUÇÃO}

No Brasil, segundo dados do Ministério da Saúde $^{2}$ dos últimos 5 anos (Data SUS), as neoplasias malignas constituem a segunda causa de morte em indivíduos com mais de 40 anos e a terceira causa de morte em todas as faixas etárias. As neoplasias malignas são responsáveis por aproximadamente $16 \%$ dos óbitos em nosso país, o que significa aproximadamente 110.000 mil mortes por ano (Brasil, 2004). Ao consideramos que estes números são subestimados, podemos destacar o impacto das neoplasias na saúde pública brasileira e mundial ${ }^{1-7}$.

Dentre as neoplasias malignas o câncer colorretal é uma das mais freqüentes, tanto em incidência como em mortalidade. Ocupa a quarta posição em incidência e a segunda causa de morte nos Estados Unidos; No Brasil, segundo estimativas do Instituto Nacional de Câncer, o câncer colorretal foi a terceira neoplasia mais incidente em 2005, com aproximadamente 26.000 casos novos e com aumento nas taxas de mortalidade ${ }^{2,5-6}$

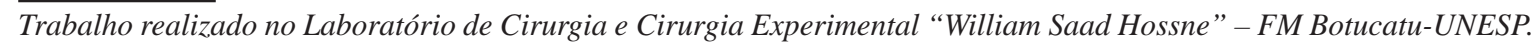

$\overline{\text { Recebido em 21 }} / 09 / 2007$

Aceito para publicação em 23/10/2007 
Rev bras Coloproct Outubro/Dezembro, 2007
Efeitos da Injeção de Solução Bicarbonatada de Ácido Acetilsalicílico em Mucosa Colorretal de Coelhos, com Vistas a Aplicação no Preparo Pré-Operatório do Cólon Enrico Salomão Ioriatti e Cols.
A despeito do grande interesse e dos investimentos dos órgãos mundiais de saúde na prevenção e no diagnóstico precoce, os índices de sobrevida em 5 anos do câncer colorretal permaneceram estáveis nas últimas décadas, ao redor de $50 \%$.

Um dos principais fatores envolvidos na sobrevida do câncer colorretal é a recidiva local. A recidiva local tem como principal causa o implante de células tumorais nas anastomoses, ${ }^{11-15}$ podendo ocorrer em até $16 \%$ dos casos. ${ }^{11}$

Diversos autores ${ }^{11-15}$ têm mostrado em pacientes portadores de câncer colorretal, a presença de células neoplásicas viáveis na luz intestinal. Estas células tumorais livres são as responsáveis pelo implante tumoral na anastomose e pela recorrência local. ${ }^{13-15}$

Neste sentido, alguns procedimentos de caráter profilático têm sido feitos no sentido de evitar tanto o implante de células na anastomose, quanto à recidiva local. Dentre eles destaca-se a lavagem química do lúmen intestinal. ${ }^{11-29}$

Os efeitos da lavagem química do lúmen intestinal sobre a viabilidade de células tumorais livres têm sido amplamente estudados. ${ }^{11-28}$ Acredita-se que, por ação mecânica e química, ela diminui a frequiência do implante tumoral na anastomose de 10-16\% para 2-3\%. ${ }^{16,27,28}$ Estudos prospectivos demonstram que a simples lavagem com solução salina reduz de maneira efetiva a viabilidade de células neoplásicas viáveis na luz intestinal. Essa redução, por sua vez, é diretamente proporcional ao volume infundido e à extensão irrigada. ${ }^{13}, 14,24,25,29$

Além da solução salina, diversas substâncias são usadas para esse fim, tais como Iodo povidone, Clorexidina, água, hipoclorito de sódio, mercúrio, noxitiolina, Gastrografin, formaldeído, entre outras. As mais comumente usadas pelos cirurgiões são o Iodo povidone e a Clorexidina; ambas apresentam efeitos citolíticos e anti-tumorais comprovados in-vitro. 14,23,24 Acredita-se que essas substâncias tenham efeito mecânico e químico na remoção de células tumorais livres. Entretanto, elas não se demonstraram muito eficazes nos testes in vivo. ${ }^{23,30}$

Em nosso meio, a solução Iodo povidone é a mais utilizada. A despeito de sua atividade anti-tumoral e citolítica comprovada, estudos experimentais em seres humanos têm demonstrado que ela é tóxica tanto a nível local quanto a nível sistêmico. ${ }^{24,25}$

Em estudos prévios, pudemos comprovar que a solução bicarbonatada de ácido acetilsalicílico (solu- ção de aspirina) tem efeitos citolíticos e anti-tumorais in-vitro. Neste estudo células tumorais VX-2 (107 células $/ \mathrm{ml}$ ) foram incubadas com diferentes concentrações da solução de aspirina (2,5\% e 5\%), sendo a viabilidade celular estudada pelo teste do azul tripan a cada 5 minutos. Observamos que a viabilidade das células tumorais diminui progressivamente e que ao final de 30 minutos todas as células tumorais estavam inviáveis. ${ }^{31}$

Em outro estudo, avaliamos os efeitos in vivo da solução de aspirina em fígado de coelhos sadios. ${ }^{32}$ Realizamos a injeção de $0,4 \mathrm{ml}$ de solução de aspirina $(2,5$ e $5,0 \%)$ e solução salina no lobo esquerdo do fígado de coelhos, em diferentes grupos experimentais. Conforme o grupo, a eutanásia ocorreu após 24 horas ou 14 dias; avaliamos peso, evolução clínica, dosagens bioquímicas, cavidades abdominal e torácica e microscopia do fígado, não sendo encontradas alterações na evolução clínica, peso e nas dosagens bioquímicas nos coelhos submetidos à injeção de solução de aspirina. ${ }^{32}$

Dessa maneira, frente à necessidade de se desenvolver novos métodos para a destruição de células tumorais livres na luz colônica e frente aos resultados obtidos em nossa linha de pesquisa, ${ }^{31-37}$ achamos oportuno estudar os efeitos da solução bicarbonatada de ácido acetilsalicílico em mucosa colônica de coelhos. A partir dos resultados pretendemos embasar eventual aplicação prática da solução bicarbonatada de ácido acetilsalicílico no preparo intestinal de pacientes portadores de câncer colorretal.

\section{OBJETIVOS}

Avaliar os efeitos da solução bicarbonatada de ácido acetilsalicílico (aspirina) na mucosa colônica normal de coelhos, embasando eventual método terapêutico para o preparo pré-operatório de cólon.

\section{MATERIAIS E MÉTODOS}

\section{1) Animais}

Foram utilizados 20 coelhos com peso aproximado de 1500 gramas.

\section{2) Técnica Cirúrgica e anestésica}

Os animais foram anestesiados por via endovenosa com a solução de pentobarbital sódico a $3 \%$ na dose de $30 \mathrm{mg} / \mathrm{kg}$. 
Rev bras Coloproct Outubro/Dezembro, 2007
Efeitos da Injeção de Solução Bicarbonatada de Ácido Acetilsalicílico em Mucosa Colorretal de Coelhos, com Vistas a Aplicação no Preparo Pré-Operatório do Cólon Enrico Salomão Ioriatti e Cols.
Após a anestesia os animais foram submetidos à laparatomia mediana, sendo identificados os segmentos do cólon sigmóide e reto. A seguir um clampe vascular foi colocado acima do cólon sigmóide e os animais foram submetidos à lavagem por via retrograda (enema) com $50 \mathrm{ml}$ da solução de aspirina ou soro fisiológico de acordo com o grupo.

Após a lavagem e esvaziamento destes segmentos, o clampe foi retirado e de acordo com o grupo, o animal foi submetido à eutanásia ou ao fechamento da laparotomia e eutanásia tardia.

\section{3) Solução teste}

O ácido acetilsalicílico utilizado foi fornecido por laboratório de manipulação e sua origem e certificações comprovadas pela Anvisa. Para a obtenção da solução a $5 \%$ foi feita a diluição de $2500 \mathrm{mg}$ de ácido acetilsalicílico em $50 \mathrm{ml}$ de bicarbonato de sódio a $10 \%$, formando a solução bicarbonatada de ácido acetilsalicílico. A solução foi preparada 2 minutos antes do seu uso.

4) Forma de análise dos resultados - Avaliação do efeito dos tratamentos

Após a retirada do segmento colônico (sigmóide e reto) a peça foi mantida e fixada em formalina tamponada a $10 \%$ por 2 dias e a seguir processada para confecção de lâminas histológicas

As lâminas foram analisadas pelo pesquisador e pelo patologista sem conhecimento prévio dos grupos experimentais.

\section{5) Protocolos e Grupos Experimentais}

\section{Protocolo 1}

Com o objetivo de avaliar o efeito imediato da solução de aspirina na mucosa colorretal de coelhos, neste protocolo os animais foram submetidos à eutanásia após o termino da lavagem (30 minutos), e foram divididos em 2 grupos experimentais:

Grupo 1 - 5 animais

Neste grupo os animais foram tratados com solução fisiológica (controle)

Grupo 2 - 5 animais

Neste grupo os animais foram tratados com a solução de aspirina.

\section{Protocolo 2}

Com o objetivo de avaliar o efeito agudo (48 horas) da solução de aspirina na mucosa colorretal de coelhos, neste protocolo os animais foram sacrificados
48 horas após o termino da lavagem (30 minutos), e foram divididos em 2 grupos experimentais:

Grupo 3 - 5 animais

Neste grupo os animais foram tratados com solução fisiológica (controle)

Grupo 4 - 5 animais

Neste grupo os animais foram tratados com a solução de aspirina.

\section{6) Resultados}

\section{Protocolo 1}

Grupo 1: Em todos os animais do grupo o procedimento não provocou alterações histológicas na mucosa (figura 1).

Grupo 2: Em todos os animais do grupo o procedimento não provocou alterações histológicas na mucosa (figura 2).

Protocolo 2

Grupo 3: Em todos os animais do grupo o procedimento não provocou alterações histológicas na mucosa (figura 3).

Grupo 4: Em todos os animais do grupo o procedimento não provocou alterações histológicas na mucosa (figura 4).

Dessa maneira, em todos os grupos estudados, com base nos resultados experimentais obtidos, observamos que:

- O tempo de exposição à solução de aspirina não modificou o padrão de resposta da mucosa;

- O tempo de sacrifício também não modificou o padrão de resposta de resposta da mucosa;

- O tipo de solução utilizada (solução de aspirina e solução fisiológica) não modificou o padrão de resposta da mucosa nos tempos estudados;

- Em todas as intervenções a mucosa se manteve preservada com criptas e epitélio de revestimento íntegros em toda sua extensão;

- Em todas as intervenções não se observaram células inflamatórias no cório da mucosa;

- Os achados, após os diferentes tempos de exposição à solução de aspirina e à solução controle, foram compatíveis com padrão normal da mucosa colônica de coelhos.

\section{DISCUSSÃO}

Em nosso meio, a solução de Iodo povidone a $5 \%$ é a solução mais comumente usada pelos cirurgiões na lavagem química do lúmen intestinal. Esta solu- 

Enrico Salomão Ioriatti e Cols.

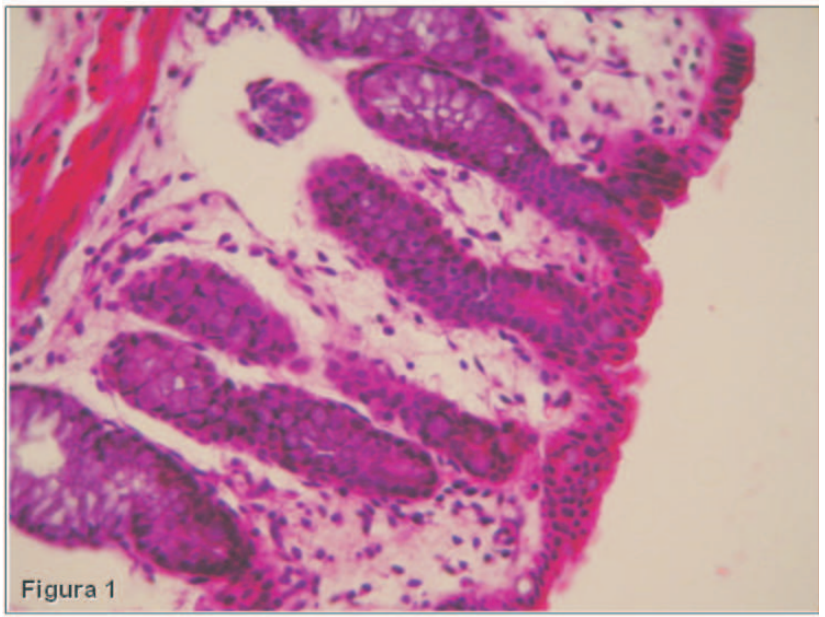

Figura 1 - Corte histológico de mucosa de cólon de coelho submetido à lavagem com solução salina por 30 minutos e submetido à eutanásia imediata, evidenciando preservação da mucosa 40X ( coloração HE).

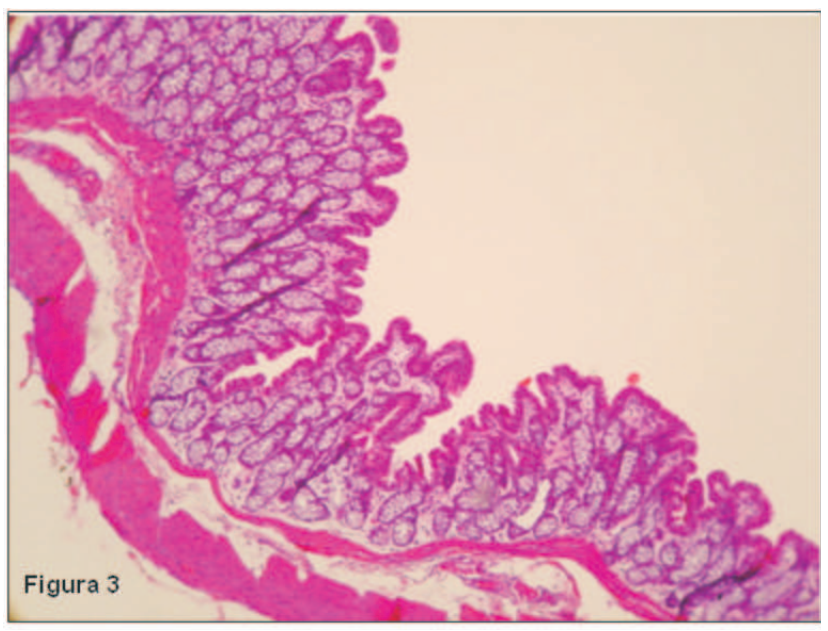

Figura 3 - Corte histológico de mucosa de cólon de coelho submetido à lavagem com solução salina por 30 minutos e submetido à eutanásia após 48 horas, evidenciando preservação da mucosa 10X (coloração HE).

ção tem efeitos citolíticos e anti-tumorais comprovados in-vitro. ${ }^{14,23,24}$ Acredita-se que essa substância tenha efeito mecânico e químico na remoção de células tumorais livres. Entretanto, ela não se demonstra eficaz nos testes in vivo. ${ }^{23}$ Isso levou alguns autores a pensar que a presença de material orgânico na luz pudesse inibir sua atividade anti-tumoral.

Esses autores analisaram, então, a influência de componentes sanguíneos e fezes sobre a atividade anti-tumoral in-vitro da solução de Iodo Povidone. ${ }^{30}$ Esse estudo demonstrou que a presença de proteínas, hemácias e sobretudo hemoglobina livre são potentes

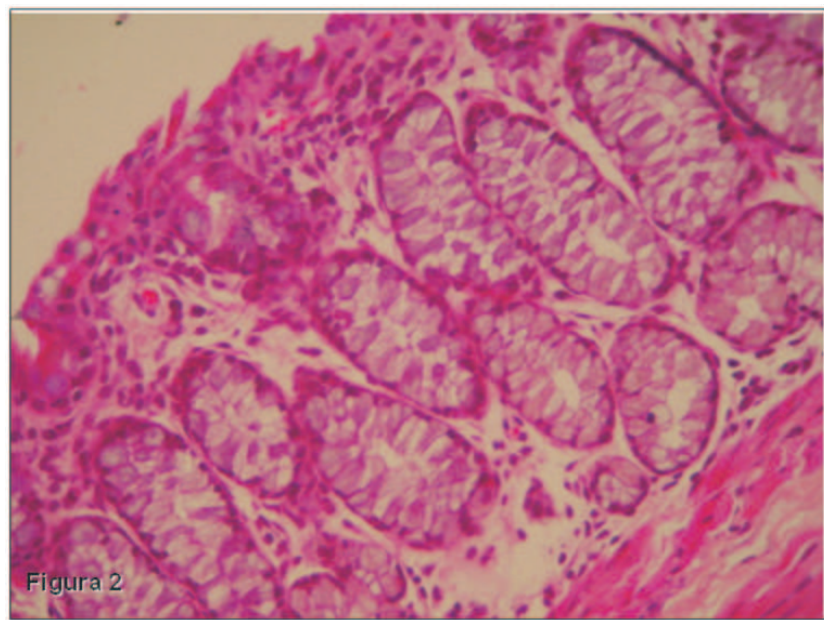

Figura 2 - Corte histológico de mucosa de cólon de coelho submetido à lavagem com solução de aspirina por 30 minutos e submetido à eutanásia imediata, evidenciando preservação da mucosa 40X (coloração HE).

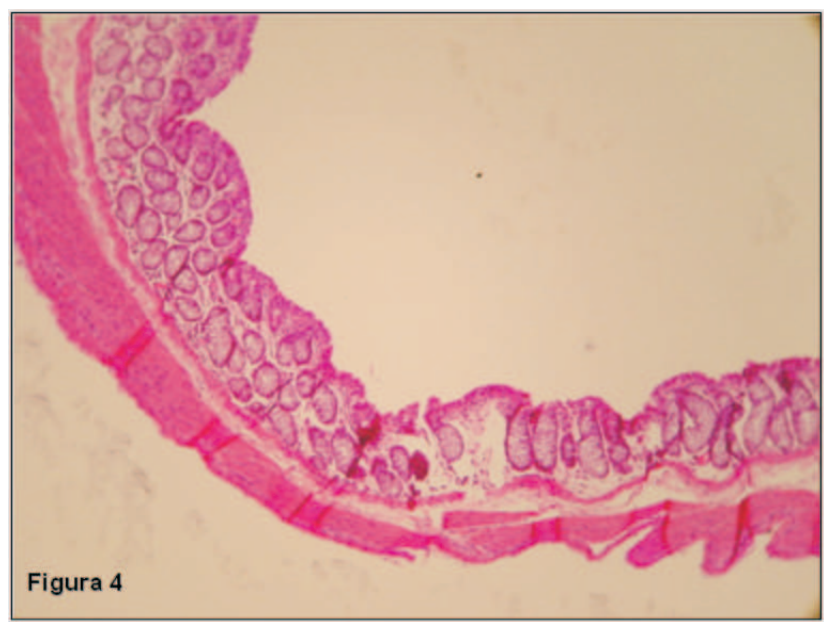

Figura 4 - Corte histológico de mucosa de cólon de coelho submetido à lavagem com solução de aspirina por 30 minutos e submetido à eutanásia após 48 horas, evidenciando preservação da mucosa 10X (coloração HE).

inibidores da atividade citolítica e anti-tumoral desta solução. ${ }^{30}$

Além de seu baixo efeito anti-tumoral in vivo, alguns estudos experimentais e em seres humanos têm demonstrado que a solução de Iodo povidone é tóxica tanto a nível local quanto a nível sistêmico.

Em estudo experimental, o efeito local do Iodo povidone a $5 \%$ foi testado em mucosa colorretal de rato. ${ }^{25} \mathrm{Em}$ um único animal se avaliou a resposta de diferentes segmentos da mucosa a diferentes tempos de exposição à solução: 5, 15, 30, 60, 90 e 120 minutos. Após 30 min de exposição, a mucosa apresentou evi- 
Rev bras Coloproct Outubro/Dezembro, 2007
Efeitos da Injeção de Solução Bicarbonatada de Ácido Acetilsalicílico em Mucosa Colorretal de Coelhos, com Vistas a Aplicação no Preparo Pré-Operatório do Cólon Enrico Salomão Ioriatti e Cols. dências de agressão, com destacamento das células epiteliais. Depois de 90 e 120 minutos a camada epitelial foi completamente destruída. ${ }^{25}$

Neste mesmo estudo foram avaliados os efeitos do Iodo povidone a $5 \%$ na mucosa de pacientes submetidos à ressecção cirúrgica de câncer colorretal ${ }^{25}$; em 90\% dos pacientes, após uma hora da realização do procedimento, observou-se descamação intensa do epitélio e após 4 horas, nesses mesmos pacientes, a camada epitelial foi completamente destruída. ${ }^{25}$ Resultados semelhantes foram demonstrados por outros autores. ${ }^{24}$

Em um estudo piloto prévio ${ }^{38}$ avaliamos a resposta da mucosa de coelhos submetidos a diferentes tempos de exposição à solução de aspirina, e submetidos a diferentes tempos de eutanásia. Os segmentos colônicos foram expostos aos tempos de 10, 20, 30, 40 e 60 minutos; a eutanásia ocorreu imediatamente após o procedimento, após 24, após 48 e após 72 horas de acordo com o grupo estudado. Em todos os grupos a solução de aspirina não provocou alteração na mucosa colônica. A partir dos resultados deste piloto criamos os protocolos do presente estudo.

No presente estudo, com base nos resultados experimentais obtidos, observamos que a solução bicarbonatada de ácido acetilsalicílico não provocou alterações na mucosa colônica normal coelhos. Nos 10 coelhos expostos à solução de aspirina - grupos $2 \mathrm{e}$ 4 - os resultados foram idênticos a todos os controles, sendo compatível com a morfologia normal da mucosa de coelhos.

Para alguns autores o destacamento e a destruição da camada epitelial poderiam propiciar condições favoráveis para implantação de células tumorais livres. Dessa maneira, ao manter a mucosa intacta, a lavagem com solução de aspirina poderia evitar o implante dessas células.

Alguns estudos demonstram a toxicidade sistêmica da solução de Iodo Povidone. ${ }^{24,}{ }^{25}$ Em paci- entes previamente hígidos submetidos à lavagem intestinal com esta solução, observou-se em todos eles uma queda significativa dos níveis dos hormônios tireoidianos que só se normalizaram após uma semana. Os níveis de Iodo na urina também se elevaram de maneira significativa, e também permaneceram elevados por cerca de uma semana.

Além do efeito químico, a lavagem do lúmen intestinal tem um forte componente mecânico na redução de células neoplásicas livres na luz. Estudos prospectivos demonstram que essa redução é diretamente proporcional ao volume infundido e à extensão irrigada. 13, 14, 24, 25, 29 Dessa maneira, a baixa toxicidade local e sistêmica da solução de aspirina permitiria a infusão de um maior volume, a uma maior extensão do cólon.

\section{CONCLUSÃO}

Com base no modelo experimental, com a metodologia empregada e tendo em vista os objetivos estabelecidos, pudemos chegar às seguintes conclusões:

1. A solução de aspirina não promove alteração na mucosa colônica de coelhos;

2. A solução de aspirina, pela sua atividade anti tumoral e citolítica, bem como por sua baixa toxicidade pode ter uma potente ação na redução da viabilidade de células tumorais livres na luz colônica.

3. Os efeitos observados embasam eventual aplicação desta solução no preparo de cólon em pacientes portadores de neoplasias colorretais, sendo necessários mais estudos para esta proposta.

\section{AGRADECIMENTOS}

Agradeço ao Laboratório de Cirurgia e Cirurgia Experimental "William Saad Hossne" que gentilmente nos forneceu o material para realização do estudo e aos seus funcionários pelo auxílio técnico.

\footnotetext{
ABSTRACT: Background: The implantation of viable exfoliated intraluminal tumour cells is the major cause of local recurrence in colorectal cancer. ${ }^{11-28}$ Therefore, the bowel lumen wash with a tumoricidal agent has been recommended. ${ }^{11-28}$ In previous study we observe that acetylsalicylic acid solution cause neoplastic cell death in vitro. ${ }^{31}$ Purpose: Assess the local effect of acetylsalicylic acid solution on the colonic mucosa of rabbits, in order to use this agent in the bowel lumen wash. Methods: 20 rabbits were used. A vascular clamp was placed on the distal colon, followed by the instillation per rectum of $50 \mathrm{ml}$ of acetylsalicylic acid solution or saline solution, according to the group. The euthanasia was performed immediately or later according to the group. Results: The acetylsalicylic acid solution doesn't cause any injury on the colonic mucosa of rabbits. Conclusion: The use of acetylsalicylic acid solution in the bowel lumen wash seems clinically feasible.
}

Key words: Cancer; Colon; Local Recurrence; Rectal Washout; Aspirin. 
Rev bras Coloproct Outubro/Dezembro, 2007
Efeitos da Injeção de Solução Bicarbonatada de Ácido Acetilsalicílico em Mucosa Colorretal de Coelhos, com Vistas a Aplicação no Preparo Pré-Operatório do Cólon Enrico Salomão Ioriatti e Cols.
Vol. 27

\section{REFERÊNCIAS}

1. Brasil. Ministério da Saúde. Datasus. Sistema de Informações sobre mortalidade, 1997. Brasília, 2001. [acesso em $2001 \mathrm{Fev}$ 16]. Disponível em: url: http://www.datasus.gov.br

2. World Health Organization-WHO. [on line]. Geneva, 1998. [cited $2001 \mathrm{Fev} 16]$. Available from: url: http:// www.who.org

3. ARMSTRONG, B.K. \& DOLL, R. Environmental factors and cancer incidence and mortality in different countries: with special reference to dietary practices. Int. J. Cancer Inst., 15:167-72, 1975.

4. BARKER, D.J.B. Rise and fall of western diseases. Nature, 338:371-2, 1989.

5. BRUMINI, R. et al. Câncer no Brasil: dados histopatológicos: 1980-2000. Ministério da Saúde: Rio de Janeiro, 2000. p. 37-9.

6. COELHO, J.C.V. Aparelho digestivo: clínica e cirurgia. 2. ed. Rio de Janeiro: Medsi, 1996. p.787-811.

7. DUKES, C.E. Cancer of the rectum on analysis of 1000 cases. J. Pathol. Bacteriol., 50:527-40, 1940.

8. GOLIGHER, J.C. Surgery of the anus, rectum and colon. 5.ed. London: Barlliere Tindal, 1989. p. 468.

9. HABR-GAMA, A Câncer no reto. In: PINOTTI, H.W. Tratado de clínica cirúrgica do aparelho digestivo. São Paulo: Atheneu, 1994. v.2, p. 1273-92.

10. HABR-GAMA, ${ }^{a}$ et al. Tumores malignos do cólon. In: DANI, R. \& CASTRO, L.P. (Eds). Gastroenterologia clínica. Rio de Janeiro: Guanabara. 1990. v. 2, p.860-71.

11. Long RT \& Edwards RH. Implantation metastasis as a cause of local recurrence of colorectal carcinoma Am J Surg 157(2):194-201, 1989 Feb.

12. Gertsch P. Baer HU. Kraft R. Maddern GJ. Altermatt HJ. Malignant cells are collected on circular staplers Diseases of the Colon \& Rectum. 35(3):238-41, 1992 Mar.

13. Jenner DC. de Boer WB. Clarke G. Levitt MD Rectal washout eliminates exfoliated malignant cells Diseases of the Colon \& Rectum. 41(11):1432-4, 1998 Nov

14. Sayfan J. Averbuch F. Koltun L. Benyamin N. Effect of rectal stump washout on the presence of free malignant cells in the rectum during anterior resection for rectal cancer. Diseases of the Colon \& Rectum. 43(12):1710-2, 2000 Dec.

15. Basha G. Penninckx F. Mebis J. Geboes K. Yap P Prevention of anastomotic tumour take by on-table colon washout with povidone-iodine. an experimental study in rats. European Surgical Research. 31(2):202-9, 1999

16. Umpleby HC, Williamson RC. The efficacy of agents employed to prevent anastomotic recurrence in colo-rectal carcinoma. Ann R Coil Surg Engl 1984;66:192-4.

17. Umpleby HC, Fermor B, Symes MO, Williamson RC. Viability of exfoliated colorectal carcinoma ceils. Br J Surg 1984;71:659-63.

18. Skipper D, Cooper AJ, Marston JE, Taylor I. Exfoliated cells and in vitro growth in cotorectal cancer. Br J Surg 1987;74:1049-52.
19. Fermor B, Umpleby HC, Lever JV, Symes MO, Williamson RC. Proliferative and metastatic potential of exfoliated colorectal cancer cells. J NatI Cancer Inst 1986;76: 347-9.

20. Kirkland SC, Bailey IG. Establishment and characteristics of six human colorectal cancer lines. Br J Cancer 1986;53:77985.

21. Rosenberg IL, Russell CW, Giles GR. Cell viability studies on the exfoliated colonic cancer cell. Br J Surg 1978;65:188-90.

22. Hubens G, Willems G. Factors influencing the implantation of colon cancer cells in the colonic suture line in rats. Eur Surg Res 1990;22:35(>-64.

23. DochertyJG, McGregor JR, Purdie CA, et al. Efficacy of tumoricidal agents in vitro and in vivo. Br J Surg 1995; 82:10502.

24. Mariani, P. P.; van Pelt, J. F.*; Ectors, N.†; Topal, B.; D’Hoore, A.; Penninckx, F. Rectal washout with cytotoxic solution can be extended to the whole colon. British Journal of Surgery Volume 89(12), December 2002, p 1540-1544

25. Basha, G.; Penninckx, F.; Mebis, J.; Filez, L.; Geboes, K.; Yap, P. Local and systemic effects of intraoperative wholecolon washout with 5 per cent povidone-iodine. British Journal of Surgery Volume 86(2), February 1999, pp 219-226

26. Vink M. Local recurrence of cancer in the large bowel: the role of implantation metastases and bowel disinfection. Br J Surg 1954; 41: 431-3.

27. Southwick HW, Harridge WH, Cole WH. Recurrence at the suture line following resection for carcinoma of the colon. Am J Surg 1962; 103: 86-9.

28. Gubareef N, Suntzeff V. Preliminary report on application of iodine in prevention of surgical dissemination of viable malignant cells. J Surg Res 1962; 2: 144-5

29. Maeda, R.; Maruta, M.; Hanai, T.; Sato, H.; Horibe, Y. Irrigation Volume Determines the Efficacy of Rectal Washout. Diseases of the Colon \& Rectum 2004; 47: 1706-1710

30. BASHA, G.; PENNINCKX, F.; YAP, P. Influence of blood components and faeces on the in vitro cancericidal activity of povidone-iodine. Br J Surg. 1998 Apr;85(4):534-7. PMID: 9607542 [PubMed - indexed for MEDLINE]

31. Saad-Hossne R, Hossne WS, Prado RG. Effects of acetylsalicylic acid and acetic acid solutions on VX2 carcinoma cells: invitro study. Acta Cir Bras. [serial on the Internet] 2006 May-June 21(3). Available from URL: http: // www.scielo.br/acb.

32. Saad-Hossne R, Prado RG, Hossne WS. Efeito da solução de ácido acetilsalicílico e de ácido acético em fígado de coelhos. Acta Cirúrgica Brasileira 2004;19:677-686.

33. CAMARA, F.R. Injeção prostática de solução esclerosante. Estudo experimental no cão. Botucatu, 1973. 115p. Tese (Doutorado em Bases Gerais e Cirurgia Experimental) - Faculdade de Medicina, Universidade Estadual Paulista.

34. CAMARA, F.R., HOSSNE, W.S., MONTENEGRO, M.R.G. Injeção prostática de solução esclerosante. Estudo experimental no cão. J. Bras. Urol., v. 2, p. 278-81, 1976. 
Rev bras Coloproct

Outubro/Dezembro, 2007
Efeitos da Injeção de Solução Bicarbonatada de Ácido Acetilsalicílico em Mucosa Colorretal de Coelhos, com Vistas a Aplicação no Preparo Pré-Operatório do Cólon
Vol. 27 $\mathrm{N}^{\circ} 4$ Enrico Salomão Ioriatti e Cols.

35. MACEDO, A.R., HOSSNE, W.S., FAIFER, J.G. Resulti della terapia sclerosanti locale nel trattamento del carcinosarcoma di Walker 256 unoriabtato nel figato. Chir. Patol. Sper., v. 27, p. 444-55, 1979.

36. Saad-Hossne R, Hossne Ws and Prado RG. Ascite neoplásica: efeito da solução aquosa de fenol, ácido acético e glicerina sobre o tumor ascítico de Ehrlich. Acta Cir. Bras., Dez 2003, vol.18, no.6, p.534-536.

37. Saad-Hossne R, hossne WS and Prado, R G. Efeito da solução aquosa de fenol, ácido acético e glicerina sobre o tumor ascítico de Ehrlich: estudo experimental in vitro. Acta Cir. Bras., Jan 2004, vol.19, no.1, p.54-58
38. Saad-Hossne, R.; Siqueira, J.M.; Rodrigues M.A.M., Ioriatti, E.S.: "Efeitos da Injeção de Solução Bicarbonatada de Acido Acetil Salicilico em Mucosa Colorretal- Estudo Experimental em Coelhos" In XXVII Congresso Brasileiro de Cirurgia, 2007, Belo Horizonte, MG. Revista do Colégio Brasileiro de Cirurgiões - vol. 34 - Julho 2007- Suplemento.

\section{Endereço para correspondência:}

ROGÉRIO SAAD-HOSSNE

Departamento de Cirurgia e Ortopedia

Faculdade de Medicina de Botucatu- UNESP

18618-970 Botucatu - SP Brasil

E-mail: saad@fmb.unesp.br 